\title{
REUTILIZAR PARA COMBATER O HOSPEDEIRO INTERMEDIÁRIO AEDES AEGYPTI: DESENVOLVENDO A SENSIBILIDADE POR MEIO DE OFICINAS
}

\author{
Isabelly Gatti Rocha Tourinho ${ }^{1}$ \\ Mauro Márcio Tavares da Silva²
}

\begin{abstract}
Resumo: $O$ estudo apresenta ações do projeto Sustentabilidade: a universidade nas Ilhas - desenvolvido pela Unama -, o qual procura, por meio de oficinas de caráter interdisciplinar, realizar atividades voltadas para estudantes da educação básica da rede púbica de ensino, residentes nas ilhas situadas ao redor da cidade de Belém-PA. O foco da ação é o Aedes aegypti hospedeiro intermediário da dengue, zika, febre amarela e chikungunya. Como forma de avaliação, foi aplicada uma pergunta antes e após a oficina, com intuito de fazer uma comparação entre os resultados. Por meio de análises qualiquatitativas, foi possível perceber um aumento de informações a respeito do assunto, concluindo que a ação foi de suma importância para a sensibilização dos participantes.
\end{abstract}

Palavras-chave: Mosquito da Dengue; Educação Ambiental; Sustentabilidade.

Abstract: The study demonstrates acts of the Sustainability project: the university in the Islands - developed by Unama -, which seeks, through interdisciplinary workshops, to carry out activities aimed for students of basic education in the public schooling network, who reside in the islands located around the city of Belém-PA. The focus of the act is Aedes aegypti - the intermediate host of dengue, zika, yellow fever and chikungunya. As a form of evaluation, a question was applied before and after the workshop, in order to make a comparison between the results. Through quali-quantitative analysis, it was possible to notice an increase of information on the subject, concluding that the act was extremely important to develop the participants' awareness on the matter.

Keywords: Dengue Mosquito; Environmental Education; Sustainability.

\footnotetext{
1 Universidade da Amazônia. E-mail: bellygatti@gmail.com. Link para o Lattes: http://lattes.cnpq.br/6559102284106126

${ }^{2}$ Universidade da Amazônia. E-mail: maurotavares10@gmail.com. Link para o Lattes: http://lattes.cnpq.br/7668097330355884
} 


\section{Introdução}

Ao longo do tempo, inúmeros foram os programas implementados com o intuito de controlar a proliferação do Aedes aegypti, principalmente em países subdesenvolvidos; entretanto grande parte dessas iniciativas não conseguiu alcançar sucesso em suas ações (HALSTEAD, 1988). Nessa perspectiva, entende-se que essas falhas ocorrem devido à ausência de condições indispensáveis para o bom funcionamento de uma sociedade, como a falta de infraestrutura, coleta de lixo adequada, abastecimento regular de água, entre outros (COELHO; DE SOUZA et al., 2018).

A dengue e outras arboviroses (como o chikungunya, zika e febre amarela) podem ser transmitidas por duas espécies principais de mosquitos do gênero Aedes, sendo estas: Aedes aegypti e Aedes albopictus (LOURENÇODE-OLIVEIRA et al., 2004; MILLER; BALLINGER, 1988). Contudo, a mais conhecida popularmente é o Ae. aegypti, que é o foco deste trabalho. Esta espécie foi descrita pela primeira vez por Linnaeus em 1762, no Egito (FOOTE, 1961), e acredita-se que foi introduzida no Brasil durante o período colonial, a partir do comércio de escravos (CONSOLI; OLIVEIRA, 1994; FORATTINI, 2002). Devido às modificações antrópicas, houve a destruição dos habitats naturais de várias espécies, mas o Aedes aegypti conseguiu se adaptar e sobreviver (CROVELLO; HACKER, 1972).

Após o período de adaptação, logo se tornaram abundantes nas cidades, pois se reproduzem com facilidade; além disso, possuem alta potencialidade de infecção por um vírus (DYE, 1992). Inúmeros são os desafios para controlar o vetor e é fundamental investir em estratégias efetivas - as quais procurem alinhar a Educação Ambiental e a sustentabilidade (RAHMEIER, 2019) - que possam despertar a sensibilidade das pessoas e assim conseguir evitar a proliferação dos mosquitos.

Sendo assim, o projeto de extensão Sustentabilidade: a universidade nas ilhas valoriza a riqueza cultural, social e ambiental presente nas ilhas e incentiva as escolas a realizarem atividades educativas, as quais procuram desenvolver a sensibilidade da população para o cuidado com o bem-estar coletivo. É válido ressaltar que essas atividades educacionais de sensibilização são extremamente importantes para o desenvolvimento das ilhas, porque entrelaçam o conhecimento científico ao saber popular, o que possibilita maior proximidade entre educandos e docentes.

Neste sentido, o presente trabalho tem como intuito desenvolver atividades educativas em contexto interdisciplinar - a partir da perspectiva cultural, social e ambiental - em ilhas situadas ao redor da cidade de Belém, ocasionando uma discussão sobre as principais características do hospedeiro da dengue e outras doenças. Além de informações sobre a forma de reprodução, transmissão e prevenção, percebemos a necessidade de maior diálogo com população desses municípios a fim de propor ações de promoção à sustentabilidade e ao conhecimento a respeito das doenças. Para verificar a 
eficácia da ação, o estudo procurou avaliar o conhecimento construído pelos alunos antes e após a oficina.

\section{Metodologia}

\section{Natureza da Pesquisa}

A pesquisa-ação foi empregada como base metodológica deste estudo. Segundo Baldissera (2001), esse percurso metodológico cria uma relação estreita entre a pesquisa e a prática participativa, ou seja, procura explorar e conhecer a condição social, podendo atuar na transformação e sensibilização da sociedade. Além disso, esse modelo de pesquisa é fundamentado pelo conhecimento científico e possibilita ao pesquisador utilizar técnicas, realizar o planejamento e coleta de dados, tendo como finalidade mudanças sociais e, consequentemente, a evolução coletiva (THIOLLET; COLETTE, 2014).

A abordagem utilizada foi a qualiquantitativa, tendo a qualitativa como foco; a quantitativa foi acrescentada de forma complementar. Freitas et al. (2000) afirma que as duas abordagens juntas constituem um trabalho de maior completude e significado. Mas para que essa aproximação de fato acontecesse, as respostas precisavam ser ordenadas e classificadas. Em função disso, aplicamos a técnica de Vasconcelos (2005), adaptando-a para este estudo. Logo, as respostas foram classificadas em: "Satisfatórias", para respostas completas e claras, referentes ao assunto abordado; "Parcialmente satisfatórias", para respostas incompletas; e "Insatisfatórias", se o participante demonstrasse não ter conhecimento sobre o assunto ou a resposta se encontrava em branco.

\section{Instrumentos e Etapas da Pesquisa}

O projeto foi realizado em junho de 2017 na Escola Integral Padre Eduardo (EIPE), localizada na ilha de Mosqueiro (Belém do Pará); e, em dezembro de 2017, na Escola Bosque (EB), localizada na ilha de Outeiro (Belém do Pará). A ação educativa contou com a participação de 30 alunos, sendo 15 alunos da EIPE e 15 alunos da EB.

Ao longo do projeto, foram utilizados os seguintes recursos:

- Papel A4, com a pergunta proposta (O que você sabe sobre o Aedes aegypti?);

- Lápis ou caneta;

- Computador e projetor, para apresentação do documentário que abordava o tema central da pesquisa;

- Garrafas pet's, barbantes de algodão e tesouras, para a construção do vaso anti-Aedes aegypti. 
A averiguação foi desenvolvida a partir da percepção dos estudantes sobre o mosquito da dengue, sem que houvesse qualquer interferência. Inicialmente, foi aplicada uma questão 1 (Q1), antes de ministrar a parte teórica da oficina, com o intuito de avaliar o conhecimento prévio dos participantes em relação ao mosquito Aedes aegypti.

Posteriormente, a parte teórica da oficina foi realizada com exibição de vídeos, explicações e discussões sobre o tema, para informá-los sobre a reprodução do mosquito, os riscos de infecção, as possíveis doenças, entre outros assuntos.

Em seguida, na parte prática da oficina, ocorreu a produção de vasos anti-Aedes aegypti com materiais reutilizados, como forma de sensibilizá-los a respeito da importância de se evitar a proliferação do mosquito e de como isso poderia ser feito em conjunto com a preservação do meio ambiente. Por fim, foi reaplicada a mesma pergunta feita antes da ação (Q2).

\section{Análise dos Dados}

Para iniciar a análise qualiquantitativa dos dados, foram comparadas as respostas do Q1 com as respostas do Q2. Em seguida, as informações foram interpretadas de forma criteriosa a fim de que os resultados apresentados obtivessem maior confiabilidade. Cada fala tem sua relevância, segundo Brandão (2003), mas algumas se repetem e é importante optar pelas mais descritivamente marcantes, mais significativas e com forte senso crítico.

Os dados foram tabulados em planilha eletrônica do programa Microsoft Excel 2010 e, para apresentação estatística dos dados, foi utilizado o percentual de respostas insatisfatórias, parcialmente satisfatórias e satisfatórias. Diante disso, caso houvesse uma diferença realmente expressiva, novas estratégias de ensino-aprendizagem seriam sugeridas, em conformidade com Da Silva e Leite (2008, p.386), os quais, em seu estudo, afirmam que

as aulas de campo permitiram o contato direto com a natureza, proporcionando vivenciar os conhecimentos de forma contextualizada, intensificando o processo de sensibilização, porque não é apenas a audição que é motivada, mas todos os sentidos, principalmente a visão. Aulas de campo possibilitam também a construção de uma visão crítica, por constituir uma prática que envolve o ver, o sentir, o participar e o estar presente. 


\section{Resultados e Discussão}

Antes de expor os resultados e iniciar as análises e discussões, primeiramente apresentaremos um panorama da realização do Projeto Ilhas. Antes de cada ação, reuniões de planejamento foram realizadas, com o objetivo de elaborar e organizar os subprojetos aplicados nas escolas que aceitaram participar das atividades. Em seguida, visitamos as instituições para viabilizar parcerias e fazer a divulgação para a comunidade (Figura 1).

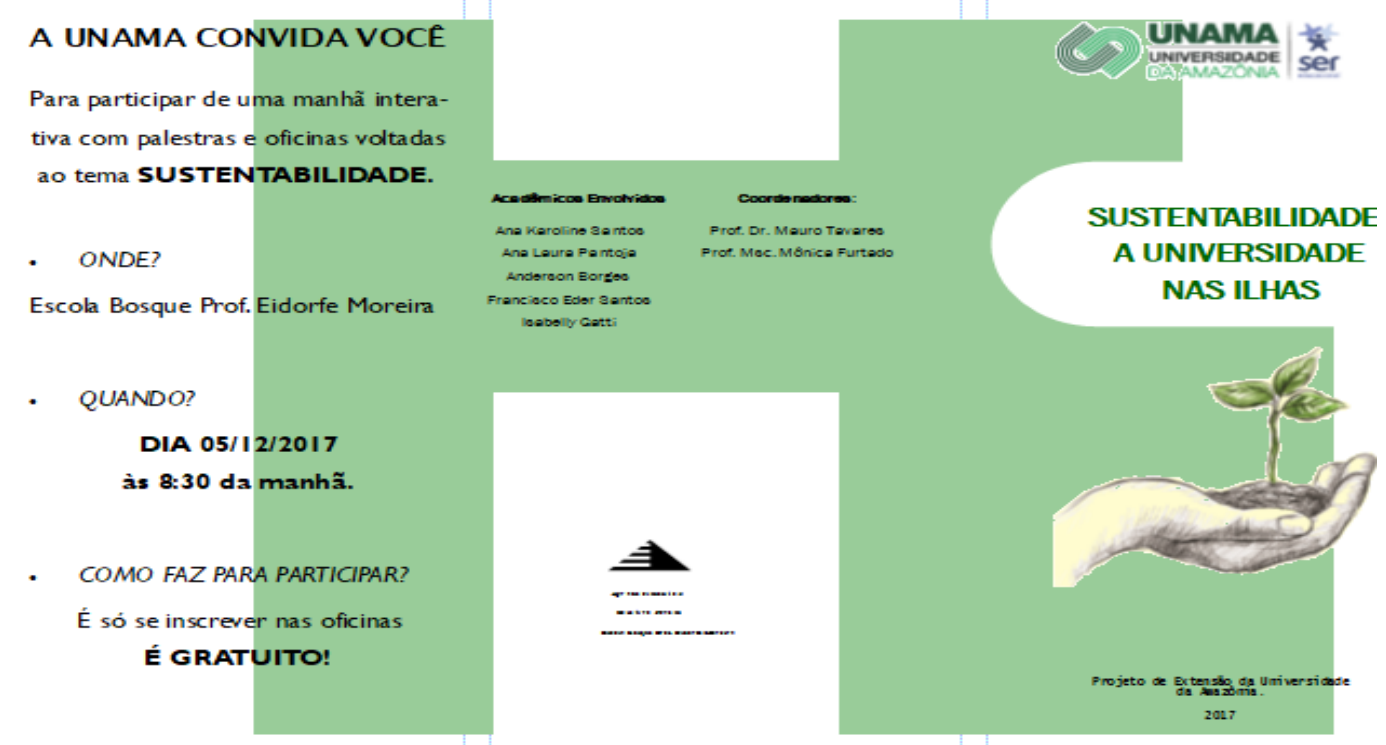

Figura 1: material utilizado na divulgação.

Fonte: autoria própria (2017).

As atividades iniciaram com a palestra "Sustentabilidade na Amazônia: princípios e conceitos" (Figura 2), que procurou introduzir e esclarecer dúvidas sobre a ação, além de dar embasamento às oficinas que posteriormente foram aplicadas. Era o início da construção da sensibilização dos educandos.

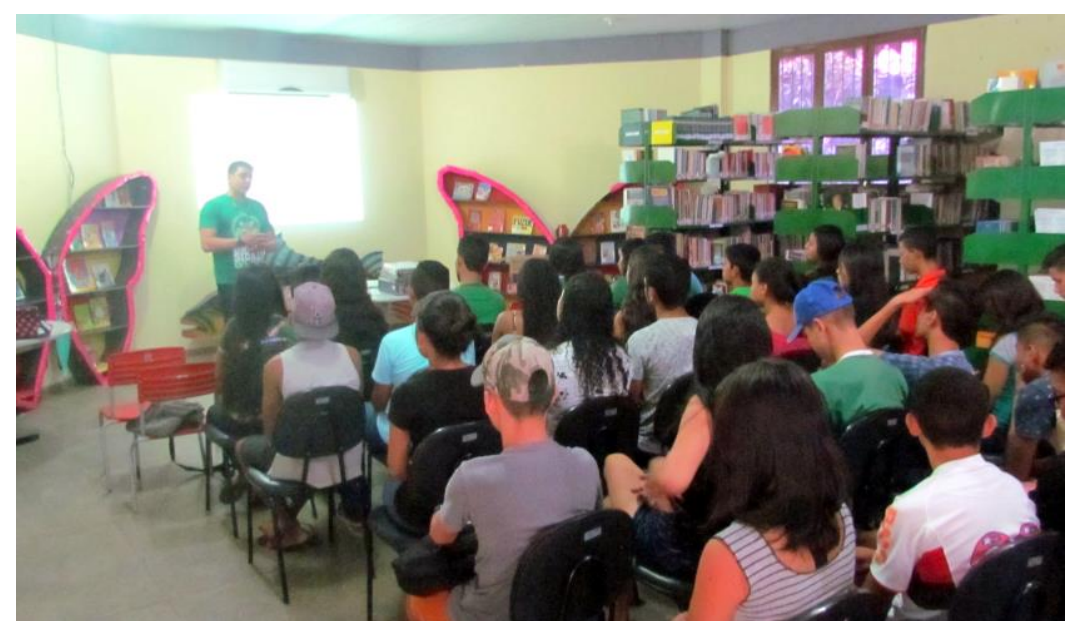

Figura 2: palestra "Sustentabilidade na Amazônia: princípios e conceitos" sendo ministrada. Fonte: autoria própria (2017). 
Em seguida, ocorreram as oficinas, que foram coordenadas pela equipe do projeto e voluntários (Figura 3). O percurso de aprendizagem ocorreu de forma satisfatória em relação às temáticas trabalhadas. $\mathrm{Na}$ oficina "Reutilizando para combater o hospedeiro intermediário Aedes aegypti" foi aplicado o questionário, o qual possibilitou a posterior análise do impacto da ação no processo de aprendizagem dos participantes.

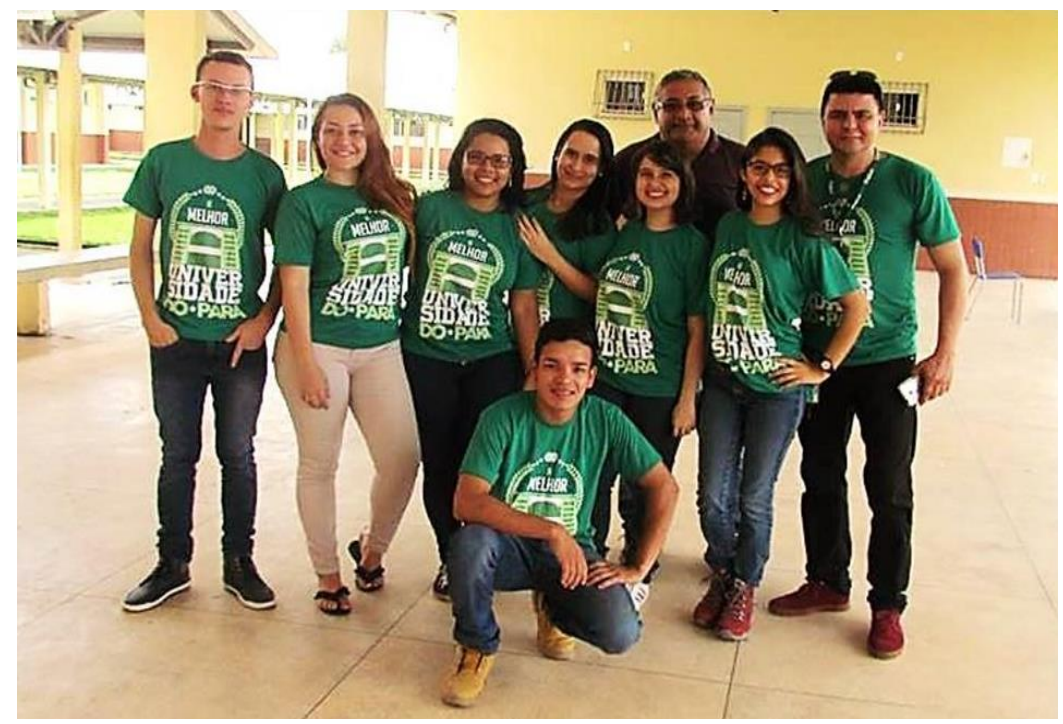

Figura 3: equipe integrante do projeto e voluntários.

Fonte: autoria própria (2017).

Após a finalização das oficinas, ocorreu a socialização das práticas realizadas (Figura 4), ou seja, o intercâmbio entre conhecimentos. Desta forma, os alunos compartilharam o que aprenderam com os participantes das outras oficinas, o que gerou em todos o entusiasmo pela busca de novos conhecimentos, além do desenvolvimento de maior senso crítico em relação aos temas ministrados.

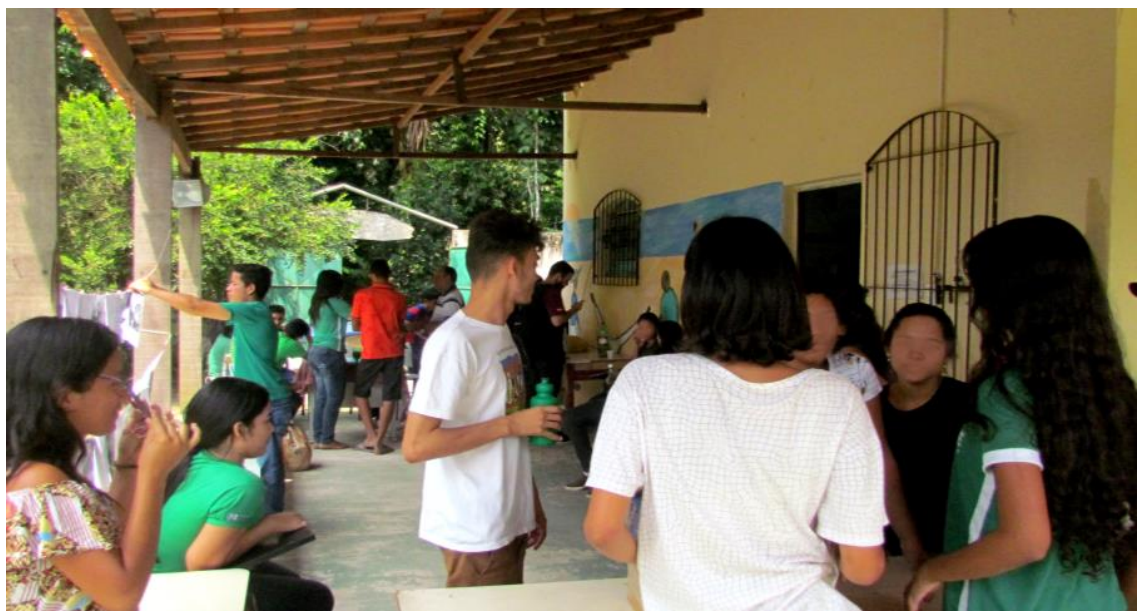

Figura 4: socialização das práticas realizadas nas oficinas.

Fonte: autoria própria (2017). 
Salientamos que foram utilizados nomes fictícios para preservar a identidade dos participantes. Isto posto, apresentamos a seguir nossos resultados, análise de dados e as discussões que permearam esta pesquisa:

\section{Percepção sobre o Aedes aegypti antes da oficina}

Iniciaremos a apresentação dos resultados com a perspectiva dos participantes da oficina comparando a EIPE e EB. O resultado anterior à ação nos revelou que as perspectivas da maioria dos alunos das duas instituições foram inferiores ao esperado, ou seja, não demonstraram ter conhecimento prévio satisfatório sobre a temática, levando em conta que a maioria das respostas foram consideradas como Parcialmente Satisfatórias (Figura 5).

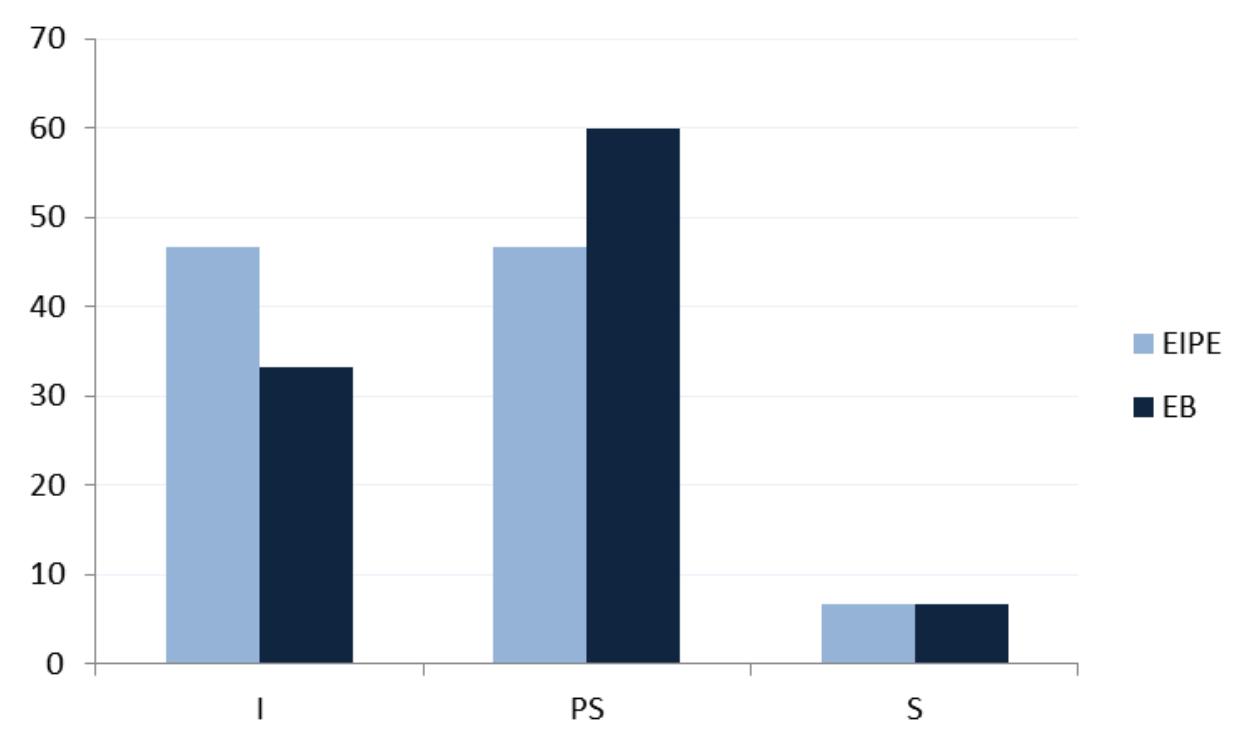

Figura 5: classificação percentual das respostas dos participantes da oficina antes da interferência educativa. S (Resposta Satisfatória), PS (Parcialmente satisfatória) e I (Insatisfatória). EIPE(Escola Integral Padre Eduardo) EB (Escola Bosque).

Fonte: pesquisa de campo (2017).

Em relação à $Q 1$ antes da ação, quando indagados sobre o conhecimento que possuíam em relação ao Aedes aegypti, ficou evidente que a maioria dos alunos já possuía um prévio conhecimento sobre o assunto, sendo $46,7 \%$ (EIPE) e $60 \%$ (EP) de respostas parcialmente satisfatórias, como:

"... água parada é um ótimo recipiente para proliferação do mosquito e que devemos evitar essa situação."

Patrícia

Entretanto, ainda assim 46,7\% (EIPE) e 33,3\% (EP) desconheciam e apenas $6,6 \%$ (EIPE) e 6,7\% (EP) conseguiram alcançar respostas satisfatórias. 
Todavia, é essencial expor resultados mais concisos e análises mais minuciosas, pois assim haverá maior clareza na compreensão dos dados; além de maior embasamento para as discussões, afinal, essa é uma das fases mais importantes da pesquisa, como declara De Oliveira $(2011$, p.46) ao enfatizar que

a análise dos dados é uma das fases mais importantes da pesquisa, pois, a partir dela, é que serão apresentados os resultados e a conclusão da pesquisa, conclusão essa que poderá ser final ou apenas parcial, deixando margem para pesquisas posteriores.

\section{Aplicação da Oficina}

A oficina foi dividida em duas etapas: uma parte teórica e outra prática. A parte teórica iniciou com a exibição de um documentário sobre o tema (Figura 6) e uma palestra complementou as orientações e esclareceu dúvidas posteriores (Figura 7). Em seguida, ocorreu a prática, com a construção do vaso de plantas anti-Aedes aegypti (Figura 8, 9 e 10). Por fim, o Q1 foi reaplicado (Q2).

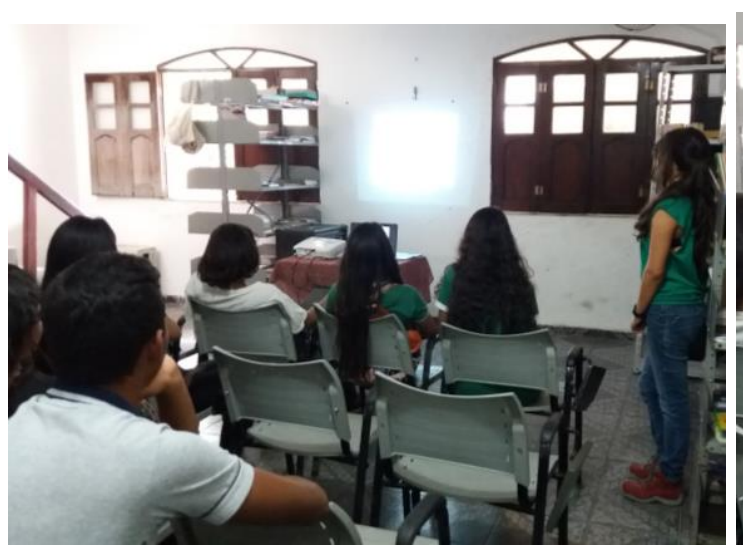

Figura 6: alunos assistindo ao documentário. Fonte: autoria própria (2017).

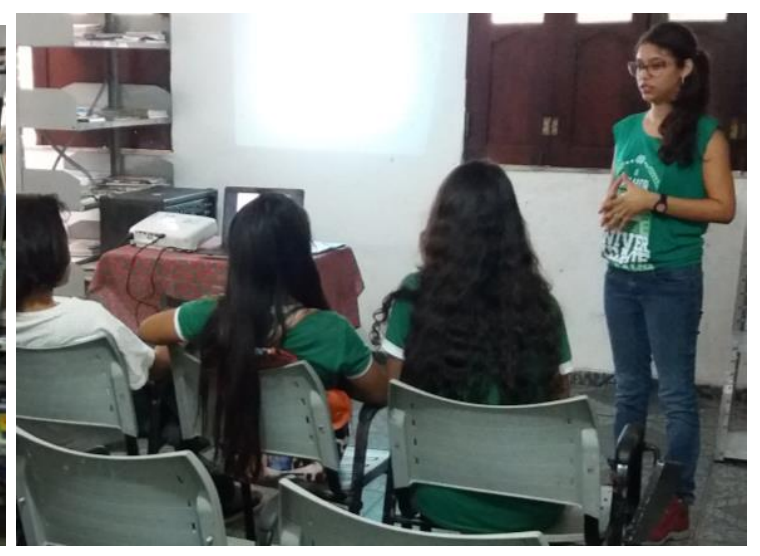

Figura 7: palestra sendo ministrada. Fonte: autoria própria (2017). 


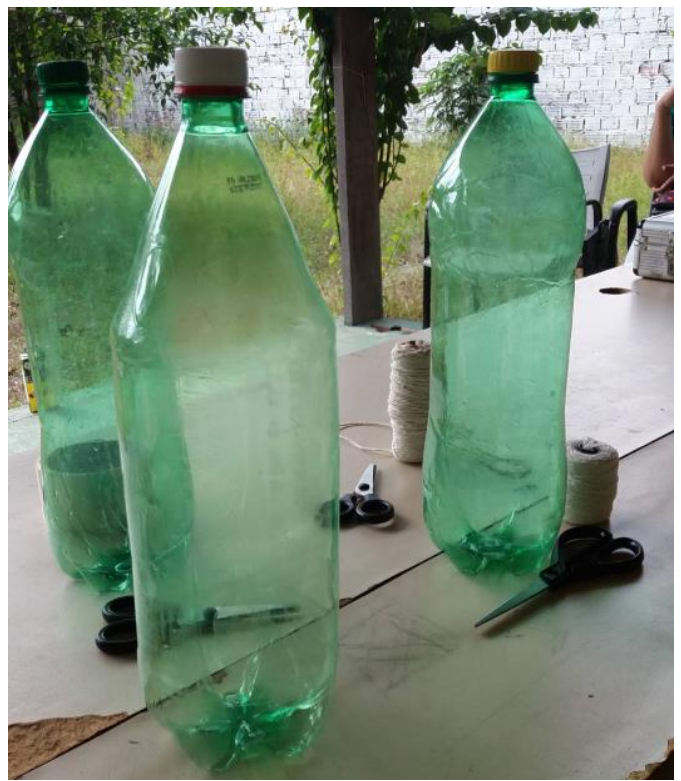

Figura 8: material utilizado na oficina. Fonte: autoria própria (2017).

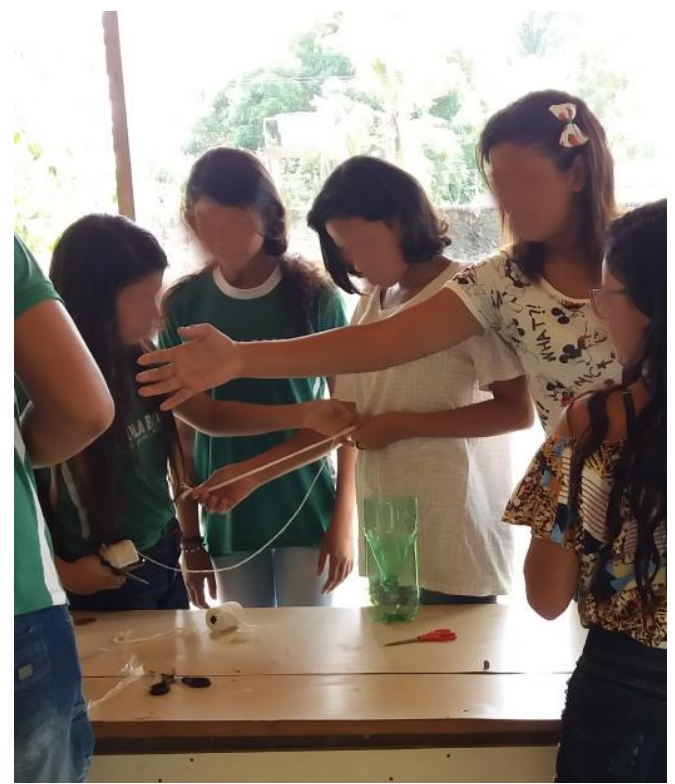

Figura 9: participantes construindo o vaso anti-Aedes aegypti. Fonte: autoria própria (2017).

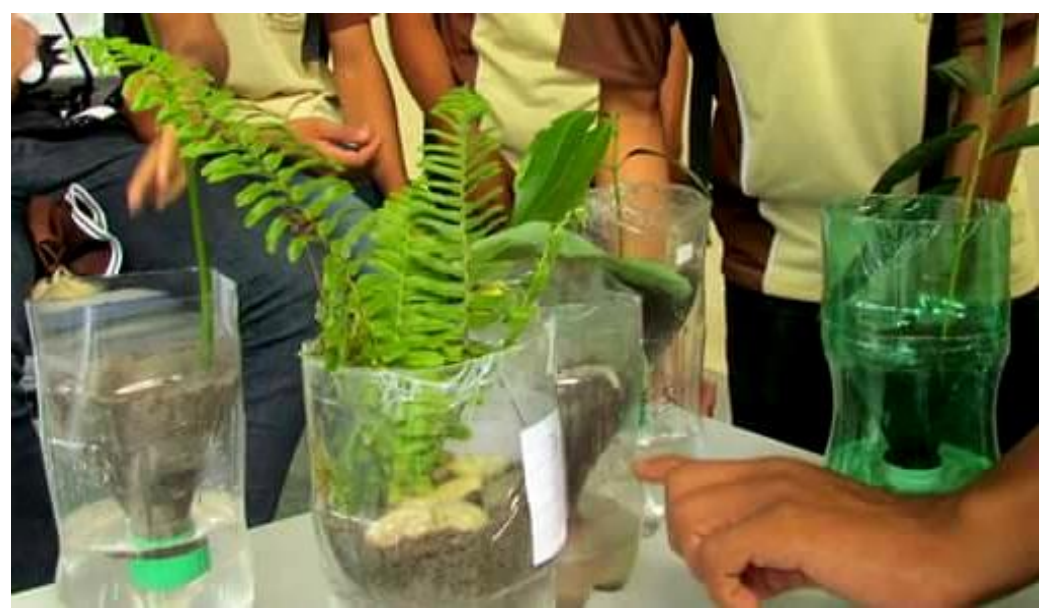

Figura 10: Socialização do vaso anti-Aedes aegypti construído na oficina "Reutilizando para Combater o Hospedeiro Intermediário Aedes aegypti".

Fonte: autoria própria (2017).

Como forma de evitar a propagação do mosquito, os vasos de plantas antidengue, como são comumente conhecidos, foram criados. O sistema deles é baseado em alta drenagem, na qual uma bandeja é acoplada para a coleta da água que, quando regada, impede o mosquito de depositar seus ovos na água, evitando sua proliferação. Em função disso, houve a ideia da construção dos vasos com materiais descartados, o que ajudaria na preservação do meio ambiente e na conscientização da importância da sustentabilidade para o mundo.

Quando são utilizadas perguntas abertas como forma de avaliação dos participantes em uma oficina, há um método empregado por inúmeros autores. 
Pessoa (2000) é um desses pesquisadores. Ele obteve resultados expressivos ao utilizar essa metodologia em seu estudo sobre as concepções etnoecológicas sobre "seres vivos e ambiente manguezal" realizado em Pernambuco - Recife com alunos da 6 ${ }^{\mathbf{a}}$ série. Para complementar e facilitar o entendimento dos participantes, foram empregados recursos audiovisuais. Trajber e Da costa (2001) atestaram que esse tipo de material incentiva a criticidade e estimula o desenvolvimento hipotético e dedutivo, assim contribuindo de forma significativa para o processo de aprendizagem do aluno.

\section{Percepção sobre o Aedes Aegipti Depois da Oficina}

Após a ação educativa, observou-se que a perspectiva dos participantes das duas instituições sobe o Aedes aegypti obteve uma melhora expressiva quando comparada ao resultado da ação anterior (Figura 11), levando em consideração que a maioria das respostas foram classificadas como satisfatória (Figura 12).

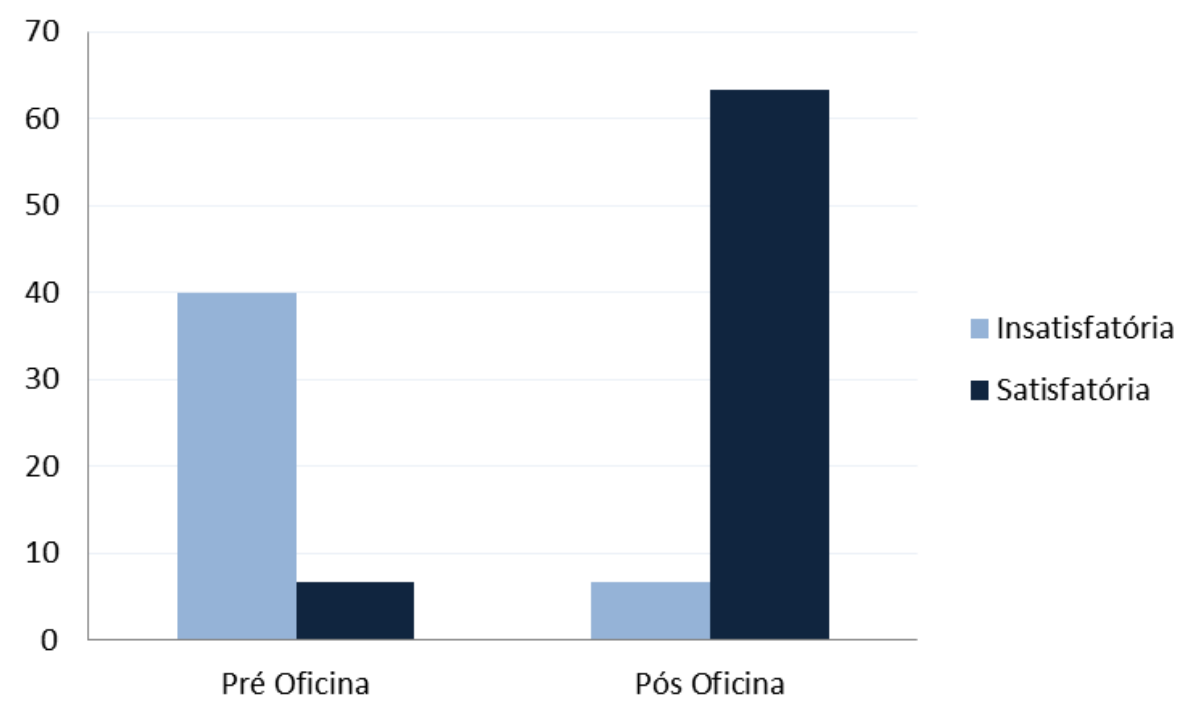

Figura 11: classificação percentual das respostas dos participantes da oficina antes e após a interferência educativa. Pré-oficina (Resposta anterior à oficina), Pós-oficina (Resposta posterior à oficina). Fonte: pesquisa de campo (2017). 


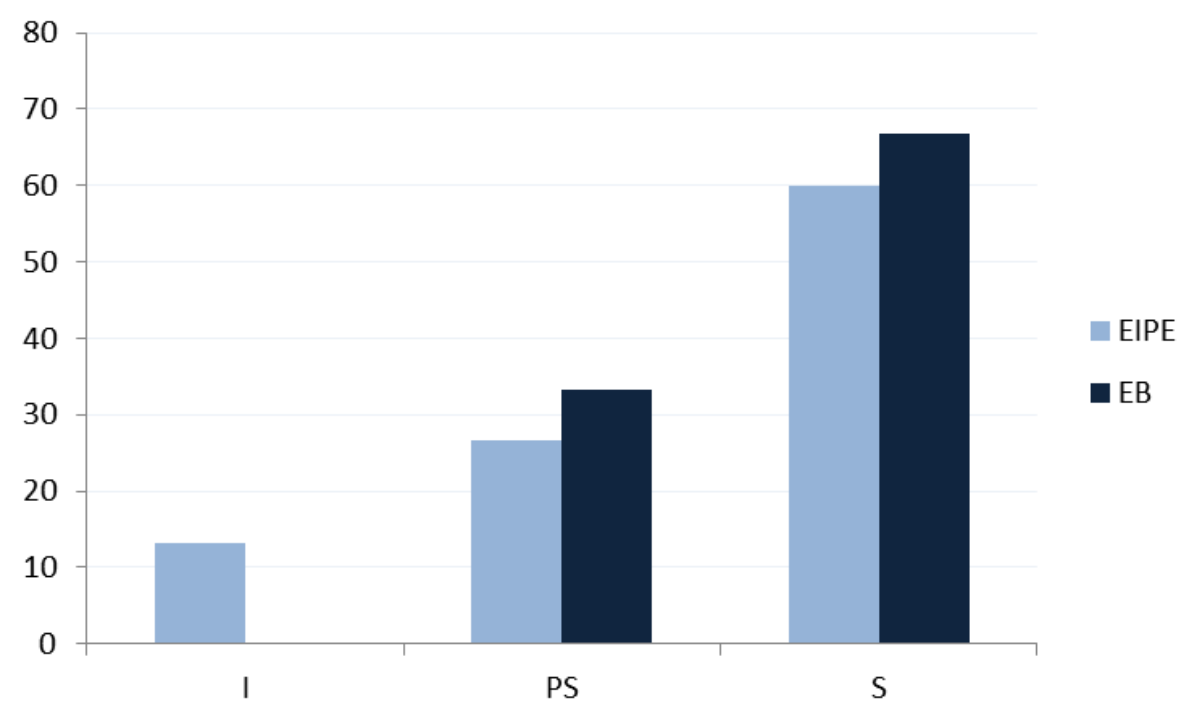

Figura 12: classificação percentual das respostas dos participantes da oficina depois da interferência educativa. S (Resposta Satisfatória), PS (Parcialmente satisfatória) e I (Insatisfatória). EIPE(Escola Integral Padre Eduardo) EB (Escola Bosque).

Fonte: pesquisa de campo (2017).

Em relação à Q2 posterior à ação, quando indagados sobre o conhecimento que possuíam em relação ao $A e$. aegypti, ficou evidente que a maioria dos alunos conseguiu alcançar respostas satisfatórias, sendo $60 \%$ (EIPE) e 66,7\% (EP), como:

"O acasalamento sexuado, o desenvolvimento da larva em água, que só a fêmea se alimenta de sangue, e que nem todos os mosquitos transmitem a dengue, zika e chikungunya."

Marcos

Respostas parcialmente satisfatória foram 26,7\% (EIPE) e 33,3\% (EP) e apenas $13,3 \%$ (EIPE) e $0 \%$ (EP) respostas insatisfatórias. Logo, os dados revelam que houve um aumento expressivo na compreensão dos educandos.

Essas informações apresentam resultados semelhantes ao estudo feito por Silva et al. (2017) que, em uma escola de ensino fundamental em Santa Cruz, realizou uma intervenção sobre o Aedes aegypti, intitulada "Ações de Educações Ambientais em Saúde no Controle do Vetor". Após a abordagem, foi possível notar a maior criticidade e acúmulo de conhecimento em relação ao tema proposto. É importante salientar que a aprendizagem não ocorre somente em sala de aula, como frisou Tourinho et al. (2020), ao expor em seu estudo o resultado do trabalho de sensibilização sobre a problemática ambiental no Centro de Ciências e Planetário do Pará (CCPP), um espaço não formal de ensino. 
Esse resultado corrobora com 0 que muitos pesquisadores $e$ educadores apontam quando se trata de Educação Ambiental e a importância de ela ser integralizada ao ensino como um todo, não apenas em momentos pontuais, como ocorre em eventos nas escolas. A falta de familiaridade com determinados temas pode gerar bloqueio na aprendizagem e, segundo Pelizzari et al. (2002), quando novas informações são incorporadas sem que haja relação com os conhecimentos que os alunos trazem, a aprendizagem não se torna tão significativa e o conhecimento pode se tornar mecânico e repetitivo.

Diante desse aspecto, é importante ultrapassar barreiras e planejar aulas e ações escolares integradoras, que procurem incluir no cotidiano escolar a Educação Ambiental. Aulas que valorizem a experiência do aluno e que permitam a ele ser corresponsável por sua aprendizagem, o que gera maior interesse e familiaridade com relação aos assuntos ministrados. Ao longo da aplicação da oficina, ficou evidente a maior conscientização por parte deles, e os resultados comprovam a eficácia da ação.

\section{Conclusões}

Desde o início das análises, houve a percepção do breve conhecimento que os alunos já possuíam em relação ao tema proposto, contudo ainda alcançavam respostas parcialmente satisfatórias. Porém, com a aplicação do Q2 foi possível observar um expressivo aumento de respostas satisfatórias, ou seja, conseguimos sensibilizar os participantes, agregar conteúdo frente ao ensino e aprendizagem e desenvolver mais criticidade com relação às questões ambientais, assim constatando a relevância de desenvolver projetos nesse viés.

Foi recompensador obter resultados válidos, demonstrando a eficiência na abordagem dos conceitos e contribuindo com novas estratégias de ensino para as instituições. Mesmo que generalizações não sejam permitidas, pelo fato de a pesquisa tratar de um estudo local, é inevitável o fato de termos contribuído de forma positiva para o ensino das escolas e esperamos que este exemplo sirva de incentivo para as pesquisas futuras.

É importante ressaltar que há a necessidade de atividades continuadas para que os processos de sensibilização e conscientização sejam alcançados com excelência. Desta forma, foi sugerida a inserção de temas relacionados ao meio ambiente no cotidiano escolar, tanto dentro quanto fora da instituição, para manter o interesse desses discentes e criar espaços de reflexão coletiva e participativa. 


\section{Agradecimentos}

Ao Conselho Nacional de Desenvolvimento Científico e Tecnológico (CNPq) e Coordenação de Aperfeiçoamento de Pessoal de Nível Superior (CAPES), pelo apoio financeiro à pesquisa; à Universidade da Amazônia (UNAMA), por tornar possível a realização deste projeto; às parcerias alcançadas com as instituições de ensino (SEDUC e SEMEC); a todos os voluntários que nos ajudaram ao longo desta jornada, especialmente ao Coletivo Jovem de Meio Ambiente - Pará (CJ/PA); e ao professor de inglês Rafael Veloso Sodré, o qual contribuiu para o desenvolvimento desta pesquisa.

\section{Referências}

BALDISSERA, A. Pesquisa-ação: uma metodologia do "conhecer" e do "agir" coletivo. Sociedade em Debate, v. 7, n. 2, p. 5-25, 2001.

BRANDÃO, C. R. A pergunta a várias mãos: a experiência da partilha através da pesquisa na educação. 2003.

COELHO, G. E. Dengue: desafios atuais. Epidemiologia e Serviços de Saúde, v. 17, n. 3, p. 231-233, 2008.

CONSOLI, R. AGB; OLIVEIRA, R. L. D. Principais mosquitos de importância sanitária no Brasil. Editora Fiocruz, 1994.

CROVELLO, T. J.; HACKER, C. S. Evolutionary strategies in life table characteristics among feral and urban strains of Aedes aegypti (L.). Evolution, p. 185-196, 1972.

DA SILVA, M. M. P.; LEITE, V. D. Estratégias para realização de Educação Ambiental em escolas do ensino fundamental. REMEA-Revista Eletrônica do Mestrado em Educação Ambiental, v. 20, 2008.

DE OLIVEIRA, M. F. Metodologia científica: um manual para a realização de pesquisas em Administração. Universidade Federal de Goiás. Catalão-GO, 2011.

DE SOUZA, J. N. et al. Prevenção contra Zika por meio da propagação de ações educativas na Escola Chuí em Maracanaú (CE). Revista Brasileira de Educação Ambiental, v. 13, n. 4, p. 379-389, 2018.

DYE, C. The analysis of parasite transmission by bloodsucking insects. Annual review of entomology, v. 37, n. 1, p. 1-19, 1992.

FOOTE, R. H. Aedes Aegypti (L.), the Yellow Fever Mosquito. Its life history, bionomics, and structure. Sir S. Rickard Christophers. Cambridge University Press, New York, 1960. xii+ 739 pp. Illus. \$14.50, 1961.

FORATTINI, O. P. Culicidologia médica: identificaçäo, biologia e epidemiologia: v. 2. In: Culicidologia médica: identificaçäo, biologia e epidemiologia: v. 2. p. 860-860, 2002. 
FREITAS, H. et al. O método de pesquisa survey. Revista de Administração da Universidade de São Paulo, v. 35, n. 3, 2000.

HALSTEAD, S. B. Aedes aegypti: why can't we control it?. Bulletin of the Society of Vector Ecologists, v. 13, n. 2, p. 304-311, 1988.

LOURENÇO-DE-OLIVEIRA, R. et al. Aedes aegypti in Brazil: genetically differentiated populations with high susceptibility to dengue and yellow fever viruses. Transactions of the Royal Society of Tropical Medicine and Hygiene, v. 98, n. 1, p. 43-54, 2004.

MILLER, B. R.; BALLINGER, M. E. Aedes albopictus mosquitoes introduced into Brazil: vector competence for yellow fever and dengue viruses. Transactions of the Royal Society of Tropical Medicine and Hygiene, v. 82, n. 3, p. 476-477, 1988.

PELIZZARI, A. et al. Teoria da aprendizagem significativa segundo Ausubel. revista PEC, v. 2, n. 1, p. 37-42, 2002.

PESSOA, R. S. Um estudo comparativo entre as concepções etnoecológicas de alunos ( $6^{\mathrm{a}}$ série) e de livros didáticos sobre os tópicos "seres vivos e ambiente manguezal". 155 f. 2000. Tese de Doutorado. Dissertação (Mestrado em Educação nas Ciências)-Universidade Federal Rural de Pernambuco, Recife, 2000.

RAHMEIER, T. Redução de focos de Aedes aegypti por meio de ações de Educação Ambiental no município de Condor (RS). Revista Brasileira de Educação Ambiental, v. 14, n. 2, p. 165-176, 2019.

SILVA, J. P. D. S. et al. AÇÕES DE EDUCAÇÕES AMBIENTAIS EM SAÚDE NO CONTROLE DO VETOR, 2017.

THIOLLENT, M. J. M.; COLETTE, M. M. Pesquisa-ação, formação de professores e diversidade. Acta Scientiarum. Human and Social Sciences, v. 36, n. 2, p. 207-216, 2014.

TOURINHO, I. G. R. et al. A importância da preservação do meio ambiente: sensibilizando os visitantes do centro de ciências e planetário do Pará. Brazilian Journal of Animal and Environmental Research, v. 3, n. 4, p. 2801-2810, 2020.

TRAJBER, R.; DA COSTA, L. B. Avaliando a Educação Ambiental no Brasil: materiais audiovisuais. Editora Fundação Peirópolis, 2001.

VASCONCELOS, F. A. L. Análise comparativa da percepção ambiental e conhecimento de alunos da rede pública e particular da Região Metropolitana do Grande Recife acerca do tema "Ambientes Recifais". 2005. $70 \mathrm{f}$. Monografia (Bacharelado em Ciências Biológicas), Universidade Federal Rural de Pernambuco, Recife, 2005. 